\title{
Puerarin attenuates inflammation and oxidation in mice with collagen antibody-induced arthritis via TLR4/NF-кB signaling
}

\author{
CHANGXING WANG, WEIDONG WANG, XIAPING JIN, JIANGUO SHEN, WEIFENG HU and TAO JIANG \\ Department of Orthopedics, The Second Affiliated Hospital of Zhejiang Chinese Medical University, \\ Hangzhou, Zhejiang 310005, P.R. China
}

Received June 30, 2015; Accepted May 5, 2016

DOI: $10.3892 / \mathrm{mmr} .2016 .5357$

\begin{abstract}
Puerarin is an important active ingredient in the root of kudzu vine due to its pharmacological properties. The aim of the present study is to contribute to the existing knowledge of the effect of puerarin in the attenuation of inflammation and oxidation in mice with collagen antibody-induced arthritis via toll-like receptor 4 (TLR4)/nuclear factor- $\mathrm{kB}$ (NF-kB) signaling. Arthritis was induced using injection of anti-type II collagen antibodies. Treatment with puerarin was observed to significantly decrease clinical scoring of the collagen antibody-induced arthritis and suppress oxidative stress and the inflammatory response in mice. Furthermore, puerarin was demonstrated to inhibit mRNA expression of matrix metalloproteinase- 9 and protein expression of TLR4 following collagen antibody-induced arthritis in mice. The effect of puerarin may be associated with the suppression of NF- $\mathrm{kB}$ activity in collagen antibody-induced arthritis mice. Furthermore, upregulation of phosphorylated (p)-Janus kinase 2 and p-signal transducer and activator of transcription 3 protein expression was suppressed by puerarin. The results of the present study indicate, for the first time, the effect of puerarin to attenuate inflammation and oxidation in mice with collagen antibody-induced arthritis via TLR4/NF- $\mathrm{KB}$ signaling.
\end{abstract}

\section{Introduction}

Osteoarthritis (OA) is a common joint disease, which is characterized by progressive articular cartilage injury with fibrillation, rhagades, anabrosis and attrition of the cartilage, accompanied by different levels of synovitis (1). OA is a major cause of joint disability in the middle aged and elderly. With

Correspondence to: Professor Weidong Wang, Department of Orthopedics, The Second Affiliated Hospital of Zhejiang Chinese Medical University, 318 Chaowang Road, Hangzhou, Zhejiang 310005, P.R. China

E-mail: weidongwangwd@yeah.net

Key words: puerarin, arthritis, inflammation, oxidation, TLR4, $\mathrm{NF}-\mathrm{KB}$ aging populations, the morbidity of $\mathrm{OA}$ is increasing year by year (2), and OA has attracted research attention. Epidemiology data demonstrates that the incidence of $\mathrm{OA}$ in middle aged and elderly population $>40$ years reaches $46.3 \%$, of these $80 \%$ demonstrate limited joint mobility (3). Effective therapy to prevent and cure OA requires understanding of the pathogenesis, however, the etiological agent of osteoarthritis remains to be elucidated despite previous studies suggesting that OA is associated with numerous factors, including senility, obesity, inflammation, trauma and heredity $(4,5)$.

Oxidation results in superoxides, hydrogen peroxide, hydroxyl radicals and other metabolic products. Excessive oxidation mediates cellular damage, oxidation of cellular lipids and proteins, and degeneration of DNA (6). Oxidation may be a pathophysiological process of OA, the disorder of antioxidant defensive system in OA patients is a critical factor of joint oxidation. Osteoarticular inflammatory diseases refer to inflammation in joints, which has a complicated pathogenesis and varying course (7). Over the last century, with the development of research in biochemistry, genetics, immunology, molecular biology and pain iconography, comprehensive studies of osteoarticular inflammatory disease have been conducted to elucidate epidemiology, etiology, clinical features, pathogenesis and differential diagnoses, and develop treatment strategies (8). Progress has been made in understanding, particularly on ankylosing spondylitis, rheumatoid arthritis (RA) and osteoarthritis.

Isoflavanones are the major components of the root of the kudzu vine, these are predominantly daidzin and puerarin. Pharmacological uses of puerarin are considered to be wide, and it may be useful in the treatment of cardiovascular and cerebrovascular diseases with further development (9). Puerarin does not result in marked proliferation of rat osteoblasts, however, it promotes the synthesis and secretion of alkaline phosphatase from osteoblasts (10). Furthermore, it may reduce bone resorption lacunae (11). Furthermore, contents of $\mathrm{Ca}^{2+}$ are reduced in the supernatant of culture solution following puerarin treatment. Via the inhibition of bone resorption, puerarin may stimulate bone formation to regulate bone metabolism (12). The aim of the present study was to improve the existing understanding of the effect of puerarin to attenuate inflammation and oxidation in mice with collagen antibody-induced arthritis via toll-like receptor 4

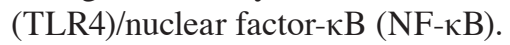




\section{Materials and methods}

Mice and experimental groups. Male DBA1/J mice (26 mice; age, 8 weeks; weight, 30-40 g) were acquired from The Second Affiliated Hospital of Zhejiang Chinese Medical University (Hangzhou, China). The mice were housed in a $22^{\circ} \mathrm{C}$ temperature controlled room with $50-60 \%$ humidity, a $12 \mathrm{~h} \mathrm{light/dark} \mathrm{cycle,} \mathrm{and} \mathrm{free} \mathrm{access} \mathrm{to} \mathrm{food} \mathrm{and} \mathrm{water.}$ The mice were randomly divided into three groups: Control group $(n=6)$, model group $(n=10)$ and puerarin group $(n=10)$. In the model and puerarin groups, DBA $1 / \mathrm{J}$ mice were injected with $4 \mathrm{mg}$ collagen antibody (clones D1, F10, A2 and D8 to collagen type II; Chemicon; EMD Millipore, Billerica, MA, USA). Mice with collagen antibody-induced arthritis in the puerarin group were injected with $100 \mathrm{mg} / \mathrm{kg}$ puerarin (chemical structure presented in Fig. 1; Sigma-Aldrich, St. Louis, MO, USA) in $20 \%$ propanediol via the tail vein for each day for 7 days. Mice in the control and model groups were injected with same volume of saline. Observational clinical scores was determined on a scale from 0 to 3, using a digital Vernier caliper (VWR International, Radnor, PA, USA) as follows: $0=$ normal paws, no swelling or redness; $1=$ swelling and/or redness in one digit or in the ankle; $2=$ swelling and/or redness in one or two digits and ankle, and $3=$ entire paw is swollen or red.

Reverse transcription-quantitative polymerase chain reaction $(R T-q P C R)$. Mice were anaesthetized and sacrificed using amobarbital $(80 \mathrm{mg} / \mathrm{kg}$; Sigma-Aldrich), then arthritis tissue samples from the knee joint were obtained and washed with phosphate-buffered saline. Total RNA was isolated from arthritis tissue samples using TRIzol (Invitrogen; Thermo Fisher Scientific, Inc., Waltham, MA, USA). Total RNA was used for cDNA synthesis by incubation with M-MLV Reverse Transcriptase (Invitrogen; Thermo Fisher Scientific, Inc.) for $1 \mathrm{~h}$ at $37^{\circ} \mathrm{C}$. qPCR was conducted using ABI 7500 Real-Time PCR System with SYBR Green Master mix (Takara Bio, Inc., Otsu, Japan). Primers used were as follows: Forward, 5'-CAC TGTAACTGGGGGCAACT-3' and reverse, 5'-CACTTC TTGTCAGCGTCGAA-3' for matrix metalloproteinase 9 (MMP-9), and forward, 5'-GGCATTGCTCTCAATGAC AA-3' and reverse, 5'-TGTGAGGGAGAT GCTCAGTG-3' for GAPDH. Cycling conditions were as follows: $94^{\circ} \mathrm{C}$ for $10 \mathrm{~min}$; followed by 40 cycles at $95^{\circ} \mathrm{C}$ for $30 \mathrm{sec}, 58^{\circ} \mathrm{C}$ for $45 \mathrm{sec}$ and $72^{\circ} \mathrm{C}$ for $45 \mathrm{sec}$; and $72^{\circ} \mathrm{C}$ for $7 \mathrm{~min}$. The mRNA expression of MMP-9 was calculated using the formula $2^{-\Delta \Delta C q}$ method (13).

Western blot analysis. Tissue samples from the knee joint $(50 \mathrm{mg})$ were harvested and homogenized, and protein extracted with radioimmunoprecipitation buffer (Beyotime Institute of Biotechnology, Haimen, China). The protein was quantified using BCA Protein assay kit (Sangon Biotech Co., Ltd., Shanghai, China). Equal quantities of proteins (50-100 $\mu \mathrm{g}$ ) were separated on 12\% SDS-PAGE gels for $20 \mathrm{~min}$ and transferred onto polyvinylidene difluoride membranes (EMD Millipore) at $100 \mathrm{~V}$ for $1 \mathrm{~h}$. The membrane was then blocked with $5 \%$ non-fat milk in Tris-buffered saline containing $0.1 \%$ Tween 20 (TBST) for $2 \mathrm{~h}$. The membrane was incubated with antibodies against TLR4 (1:2,000; cat. no. 14358; Cell Signaling Technology, Inc.,

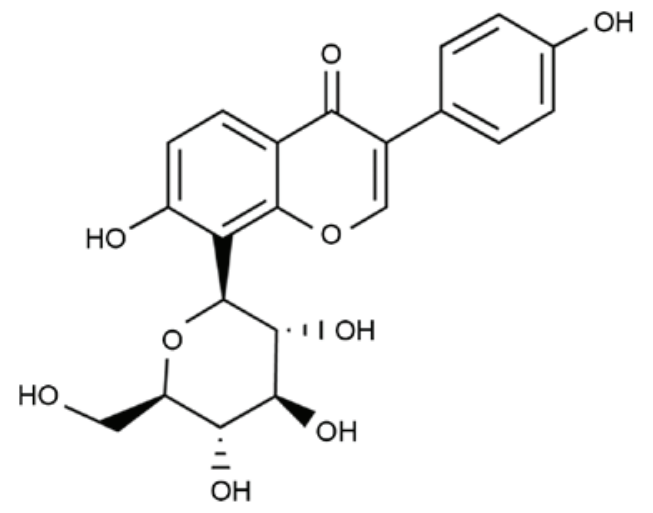

Figure 1. Chemical structure of puerarin.

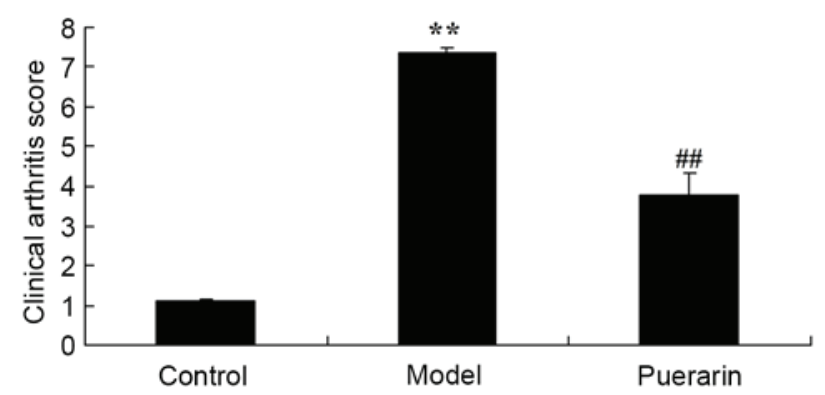

Figure 2. Observational clinical scores. ${ }^{* *} \mathrm{P}<0.05$ vs. the control group, ${ }^{\# \#} \mathrm{P}<0.05$ vs. the model group.

Danvers, MA, USA), phosphorylated Janus kinase 2 (p-JAK2; 1:2,000; cat. no. 8082; Cell Signaling Technology, Inc.), p-signal transducer and activator of transcription 3 (p-STAT3; 1:2,000; cat. no. 9145; Cell Signaling Technology, Inc.) and $\beta$-actin (1:2,000; cat. no. BB-2101-2; BestBio, Shanghai, China) overnight at $4^{\circ} \mathrm{C}$ with agitation. Following washing with TBST and incubated with anti-rabbit immunoglobulin $\mathrm{G}$ secondary antibodies (1:5,000; cat. no. BB-2202-1; BestBio) for $2 \mathrm{~h}$. The membrane was visualized with an enhanced chemiluminescence kit (cat. no. BB-3501-3; BestBio) according to the manufacturer's protocols and exposed to X-ray film. Protein levels were assessed using MacBiophotonics Image $\mathbf{J}$ software (version 1.41a; imagej.net/mbf)

Activitiy of malondialdehyde (MDA), superoxide dismutase (SOD), tumor necrosis factor- $\alpha$ (TNF- $\alpha)$, interleukin-6 (IL-6), caspase-3 and $N F-\kappa B$. Commercial ELISA kits were used to determine the levels of MDA (cat. no. BB-4709-1; BestBio), SOD (cat. no. BB-4710-2; BestBio), TNF- $\alpha$ (cat. no. H052; Nanjing Jiancheng Biological Engineering Institute, Nanjing, China), IL-6 (cat. no. H007; Nanjing Jiancheng Biological Engineering Institute) and caspase-3 (cat. no. BB-4106-2; BestBio) in knee joint arthritis samples, according to the manufacturer's protocols.

Statistical analyses. Data are presented as the mean \pm standard deviation. SPSS 11.0 software (SPSS, Inc., Chicago, IL, USA) was used to perform one-way analysis of variance and Fisher's protected least significant difference test. $\mathrm{P}<0.05$ was considered to indicate a statistically significant result. 

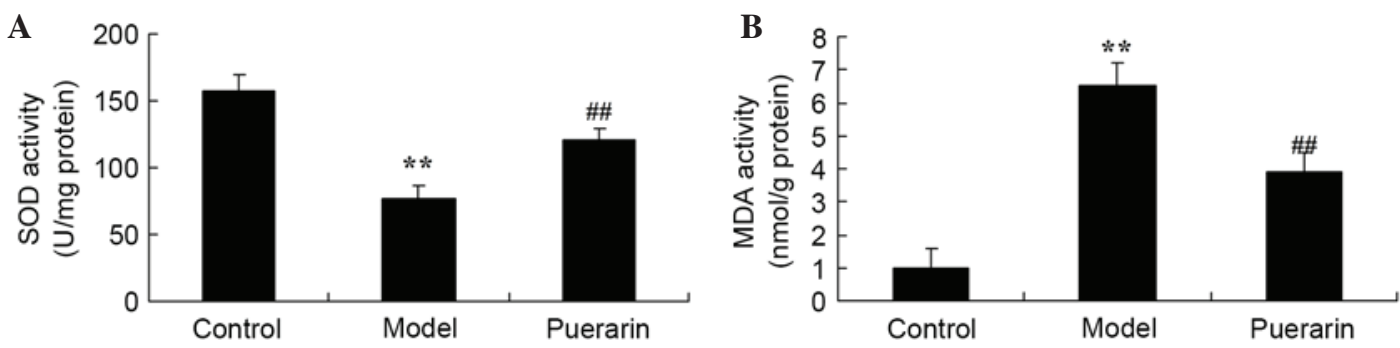

Figure 3. Oxidative stress in mice with collagen antibody-induced arthritis. (A) SOD and (B) MDA levels in collagen antibody-induced arthritis mice. ${ }^{* *} \mathrm{P}<0.05$ vs. the control group, ${ }^{\# \#} \mathrm{P}<0.05$ vs. the model group. SOD, superoxide dismutase; MDA, malondialdehyde.
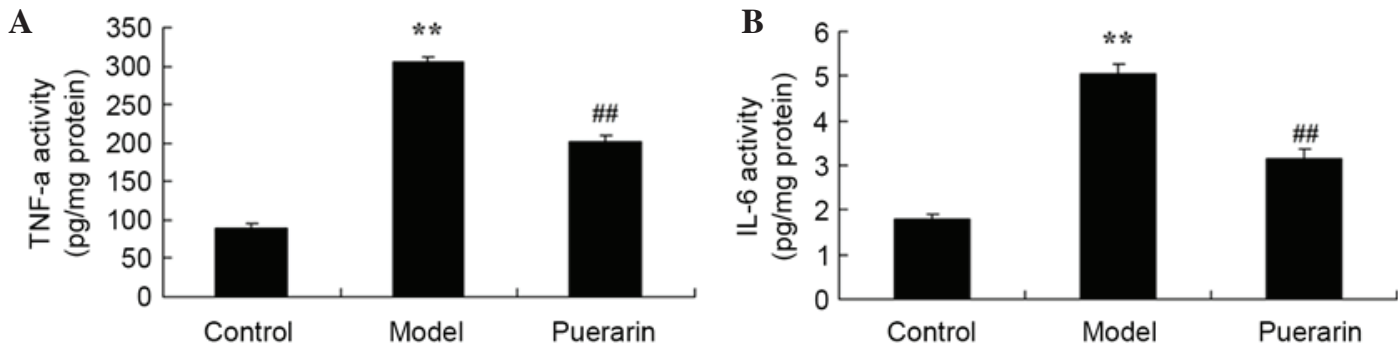

Figure 4. Inflammatory response in mice with collagen antibody-induced arthritis. (A) TNF- $\alpha$ and (B) IL-6 levels in collagen antibody-induced arthritis mice. ${ }^{* *} \mathrm{P}<0.05$ vs. the control group, ${ }^{\# \#} \mathrm{P}<0.05$ vs. the model group. TNF- $\alpha$, tumor necrosis factor- $\alpha$; IL-6, interleukin-6.

\section{Results}

Observational clinical scores were decreased in puerarin treated mice. The effect of puerarin on observational clinical scores in mice with collagen antibody-induced arthritis was examined. As presented in Fig. 2, observational clinical scores were significantly increased in the collagen antibody-induced arthritis group compared with the non-arthritis control mice $(\mathrm{P}<0.05)$. Treatment of arthritis mice with $100 \mathrm{mg} / \mathrm{kg}$ puerarin for 7 days significantly reduced the observational clinical scores in collagen antibody-induced arthritis mice compared with the model mice $(\mathrm{P}<0.05$; Fig. 2$)$.

Treatment with puerarin decreases the oxidative stress observed in mice with collagen antibody-induced arthritis. The effect of puerarin on oxidative stress damage in arthritis was also investigated. As presented in Fig. 3, there was a significant increase in oxidative stress, indicated by decreased SOD level and increased MDA level in collagen antibody-induced arthritis mice as compared with normal rats $(\mathrm{P}<0.05)$. However, treatment with $100 \mathrm{mg} / \mathrm{kg}$ puerarin for 7 days significantly decreased the suppression of the SOD level and increase in MDA level observed in collagen antibody-induced arthritis mice $(\mathrm{P}<0.05$; Fig. 3$)$.

Treatment with puerarin decreases the inflammatory response observed in mice with collagen antibody-induced arthritis. The effect of puerarin on the inflammatory response in mice with collagen antibody-induced arthritis was analyzed. As presented in Fig. 4, there was a significant increase in TNF- $\alpha$ $(\mathrm{P}<0.05)$ and IL-6 levels $(\mathrm{P}<0.05)$ in collagen antibody-induced arthritis mice compared with the control mice. Treatment of arthritis model mice with $100 \mathrm{mg} / \mathrm{kg}$ puerarin for 7 days significantly inhibited the promotion of TNF- $\alpha(\mathrm{P}<0.05)$ and

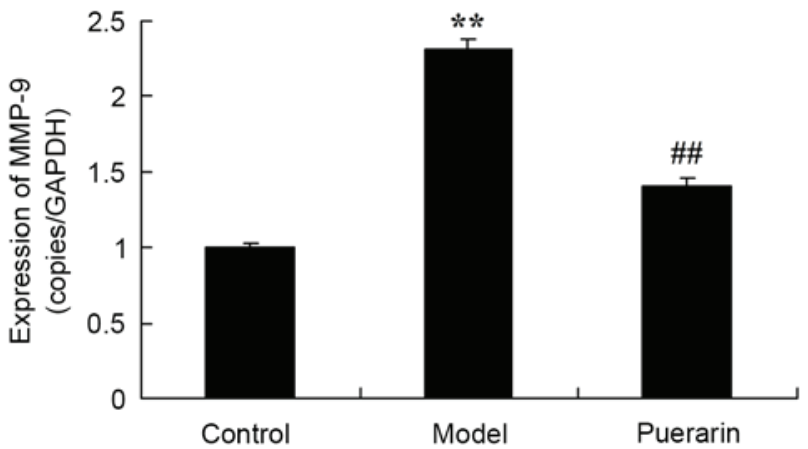

Figure 5. MMP-9 mRNA expression levels in mice with collagen antibody-induced arthritis. ${ }^{* *} \mathrm{P}<0.05$ vs. the control group, ${ }^{\# \#} \mathrm{P}<0.05$ vs. the model group. MMP-9, matrix metalloproteinase-9.

IL-6 $(\mathrm{P}<0.05)$ levels in collagen antibody-induced arthritis mice (Fig. 4).

Treatment with puerarin decreases MMP-9 mRNA expression in mice with collagen antibody-induced arthritis. The potential mechanism underlying mechanism for the effect of puerarin on collagen antibody-induced arthritis was investigated. As presented in Fig. 5, the mRNA expression of MMP-9 was significatntly increased in collagen antibody-induced arthritis mice as compared with control mice $(\mathrm{P}<0.05)$. However, the mRNA expression of MMP-9 was significantly suppressed following treatment with $100 \mathrm{mg} / \mathrm{kg}$ puerarin for 7 days in collagen antibody-induced arthritis mice $(\mathrm{P}<0.05$; Fig. 5).

Treatment with puerarin decreases TLR4 protein expression in mice with collagen antibody-induced arthritis. Western blot analysis demonstrated that the protein expression of TLR4 was significantly increased in mice with collagen 
A

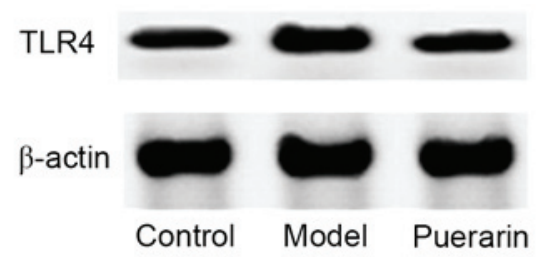

B

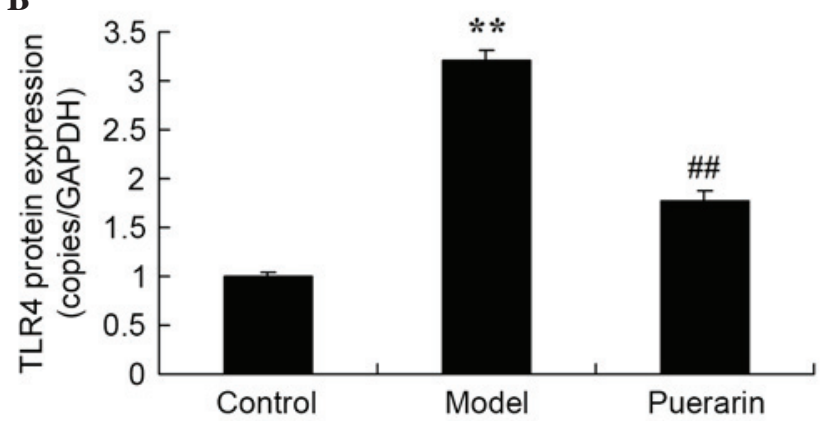

Figure 6. TLR4 protein expression in mice with collagen antibody-induced arthritis. (A) The protein expression of TLR4 demonstrated by western blotting and (B) quantification of TLR4 expression levels in mice with collagen antibody-induced arthritis. ${ }^{* *} \mathrm{P}<0.05$ vs. the control group, ${ }^{\# \prime} \mathrm{P}<0.05$ vs. the model group. TLR4, toll-like receptor 4 .

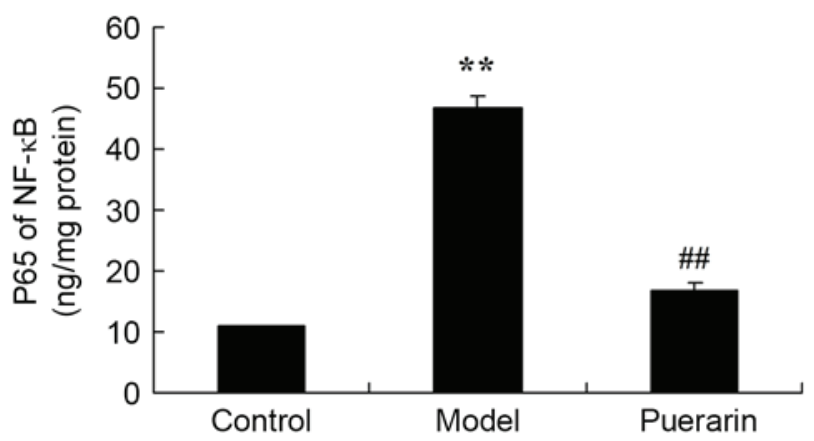

Figure 7. Activity of $\mathrm{p} 65-\mathrm{NF}-\mathrm{\kappa} B$ in mice with collagen antibody-induced arthritis determined by ELISA. ${ }^{* *} \mathrm{P}<0.05$ vs. the control group, ${ }^{\# \#} \mathrm{P}<0.05$ vs. the model group. NF- $\mathrm{kB}$, nuclear factor- $\kappa \mathrm{B}$.

antibody-induced arthritis, compared with the control group $(\mathrm{P}<0.05$; Fig. 6). Treatment with $100 \mathrm{mg} / \mathrm{kg}$ puerarin for 7 days significantly suppressed the increase in TLR4 protein expression levels in collagen antibody-induced arthritis mice (P<0.05; Fig. 6).

Treatment with puerarin decreases the activity of $N F-\kappa B$ in mice with collagen antibody-induced arthritis. Compared with the control group, collagen antibody-induced arthritis increased the activity of NF-אB $(\mathrm{P}<0.05$; Fig. 7). Treatment with $100 \mathrm{mg} / \mathrm{kg}$ puerarin for 7 days significantly reduced the activity of NF- $\mathrm{KB}$ in mice with collagen antibody-induced arthritis $(\mathrm{P}<0.05$; Fig. 7).

Treatment with puerarin decreases the protein expression levels of p-JAK2 in mice with collagen antibody-induced arthritis. A significant increase in the protein expression of p-JAK2 was observed in mice with collagen antibody-induced arthritis $(\mathrm{P}<0.05$; Fig. 8). Administration of $100 \mathrm{mg} / \mathrm{kg}$
A

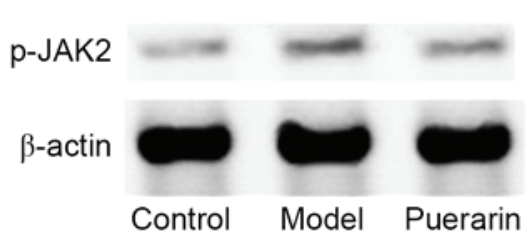

B

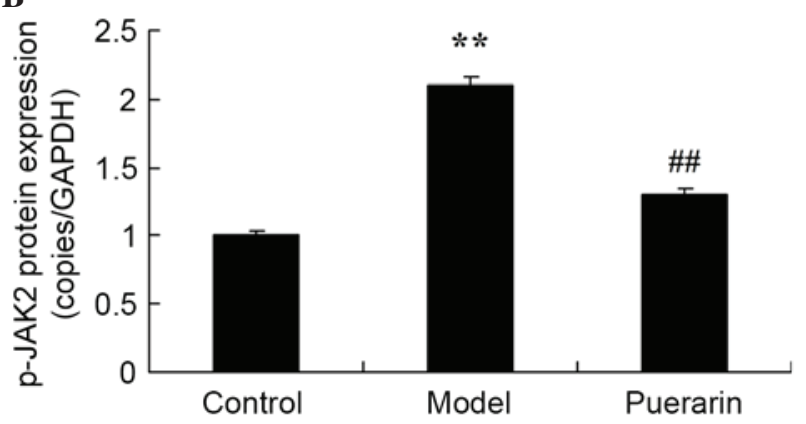

Figure 8. Protein expression of p-JAK2 in mice with collagen antibody-induced arthritis. (A) The protein expression of p-JAK2 by western blotting and (B) quantification of p-JAK2 in mice with collagen antibody-induced arthritis. ${ }^{* *} \mathrm{P}<0.05$ vs. the control group, ${ }^{\# \#} \mathrm{P}<0.05$ vs. the model group. p-JAK2, phosphorylated-Janus kinase 2 .

A
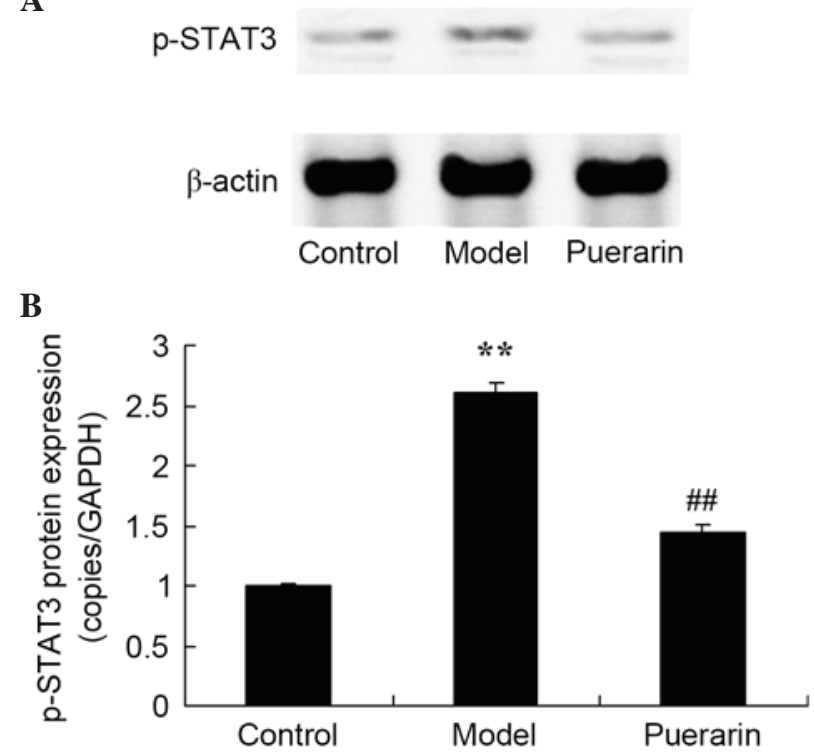

Figure 9. Protein expression of p-STAT3 in mice with collagen antibody-induced arthritis. (A) The protein expression of p-STAT3 by western blotting assays and (B) quantification of p-STAT3 in mice with collagen antibody-induced arthritis. ${ }^{* *} \mathrm{P}<0.05$ vs. the control group, ${ }^{\# \#} \mathrm{P}<0.05$ vs. the model group. p-STAT3, phosphorylated-signal transducer and activator of transcription 3 .

puerarin for 7 days significantly suppressed the increase in p-JAK2 protein expression levels in mice with collagen antibody-induced arthritis ( $\mathrm{P}<0.05$; Fig. 8).

Treatment with puerarin decreases protein expression of $p$-STAT3 in mice with collagen antibody-induced arthritis. Furthermore, as presented in Fig. 9, the protein expression of p-STAT3 in mice with collagen antibody-induced arthritis was increased compared with the control group $(\mathrm{P}<0.05)$. However, puerarin significantly suppressed the increase in 
p-STAT3 protein expression levels in mice with collagen antibody-induced arthritis $(\mathrm{P}<0.05$; Fig. 9).

\section{Discussion}

RA is a chronic autoimmune disease with pathological features that include proliferation and invasion of synovial membranes, which may form invasive pannus and result in damage to bone and cartilage (14). Frequently used biological agents against B cells, T cells and non-inflammatory factors are effective in $70 \%$ of OA patients, however, other patients continue to struggle disability (15). In the current study, puerarin significantly decreased the observed clinical scores of collagen antibody-induced arthritis in the model mice $(\mathrm{P}<0.05)$.

As an important product of lipid oxidation, MDA is widely used to indicate levels of reactive oxygen species (ROS) lipid oxidation (16). A previous study demonstrated that ROS lipid oxidation in serum and synovial fluid of OA patients is abnormal. SOD is an important enzyme that acts against ROS to decrease oxidative stress (17). Conversion of ROS superoxide anion into hydrogen peroxide, an organism can reduce oxidative damage to the articular cartilage. The glutathione (GSH) system is a key antioxidant (18). The GSH system decreases ROS levels and constitutes glutathione peroxidase, glutathione transferase and glutathione (18). It was observed that puerarin significantly suppressed the decrease in SOD level and increase in MDA level in collagen antibody-induced arthritis mice (each $\mathrm{P}<0.05$ ).

Inflammatory cytokines are important in the apoptosis of cartilage cells. The genesis and progression of OA is closely associated with cartilage injuries as a result of arthritis (19). When cells are under inflammatory stress or injured, abnormal mechanical stress results in activation of cartilage cells to stimulate macrophages to produce a series of inflammatory mediators. TNF- $\alpha$ is an important in inflammation of whole body and apoptosis of cartilage cells (20). During the pathogenesis of OA, IL-1 $\beta$ is an important cytokine for the degradation of cartilage matrix and the destruction of articular cartilage. IL-1 $\beta$ is also key in the synthesis and degradation of extracellular matrix of articular chondrocytes. The results of the present study suggest that puerarin significantly inhibits the increase in TNF- $\alpha$ and IL-6 levels in collagen antibody-induced arthritis mice $(\mathrm{P}<0.05)$.

TLRs are transduction receptors of transmembrane signals, they have been observed to be highly conserved in living organisms. They recognize invasive pathogenic microorganisms as a component of the natural immune system and are involved in the initiation and regulation of the immune response (21). Endogenous ligands from pathogenic microorganisms activate and initiate downstream TLR signal transduction pathways in synovial fibroblasts (22). Thus, inflammation-associated cytokines are produced. Previous studies have demonstrated that the expression of TLRs is increased at areas of damage to the cartilage and synovium (23). The signal transduction pathway of TLRs is involved in damage to articular cartilage and synovium, thus, OA may be associated with TLRs and the innate immune response, which is mediated by its downstream signaling pathways (21). In the present study, puerarin significantly suppressed the increase of TLR4 protein expression in collagen antibody-induced arthritis mice $(\mathrm{P}<0.05)$.
Cytokines are micromolecule polypeptides, which transmit signals for, mediate and regulate the immune system and inflammation. The regulation of the immune system depends on the equilibrium of pro-inflammatory cytokines and suppression of inflammatory cytokines. Furthermore, it also depends on the regulation of its signal transduction pathway. JAK/STAT is an important signaling pathway to mediate cytokine signal transduction. The regulation of the JAK/STAT signaling pathway is predominantly manifested by the phosphorylation of its target proteins (24). The phosphorylation of associated proteins and the subsequent signaling cascade magnifies signals, and increased spread and signal mediation is observed. During the development of RA, STAT3 remains in an activated state. Expression levels of p-STAT3 are increased and transmitted into the cell nucleus, which induces transcription of target genes. Via biological effects, including inhibition of apoptosis of fibroblast-like synoviocytes and the promotion of T cell survival, the inflammatory response may worsen (25). Consequently, a therapy targeting the activity of p-STAT3 may achieve an anti-inflammatory effect (25). In the current study, puerarin significantly reduced $\mathrm{NF}-\kappa \mathrm{B}$ activity, and suppressed p-JAK2 and p-STAT3 protein expression levels in mice with collagen antibody-induced arthritis (all $\mathrm{P}<0.05)$. This is consistent with previous studies that demonstrated puerarin attenuates NF- $\kappa \mathrm{B}$ activity in rats with chronic alcohol-induced liver injury (26), and suppressed the JAK2/STAT3 signaling pathway in rat non-alcoholic fatty liver disease (27).

In conclusion, the effect of puerarin decreases clinical scoring of arthritis, and inhibits inflammation and oxidative damage in mice with collagen antibody-induced arthritis. A possible underlying mechanism is the inhibition of inflammatory processes via suppressed TLR4/NF- $\mathrm{BB}$ and JAK2/STAT3 signaling pathways. The present study also suggests that puerarin may be useful as a novel agent for the treatment of arthritis.

\section{Acknowledgements}

The present study was supported by Zhejiang Chinese Medicine Supporting Project for Young Scientists (grant no. 2008YA010) and the Natural Science Foundation of Zhejiang Province (grant no. LY13H270007).

\section{References}

1. Zhong Y, Huang Y, Santoso MB and Wu LD: Sclareol exerts anti-osteoarthritic activities in interleukin-1 $\beta$-induced rabbit chondrocytes and a rabbit osteoarthritis model. Int J Clin Exp Pathol 8: 2365-2374, 2015.

2. Laufer Y and Dar G: Effectiveness of thermal and athermal short-wave diathermy for the management of knee osteoarthritis: A systematic review and meta-analysis. Osteoarthritis Cartilage 20: 957-966, 2012.

3. Burrows NJ, Booth J, Sturnieks DL and Barry BK: Acute resistance exercise and pressure pain sensitivity in knee osteoarthritis: A randomised crossover trial. Osteoarthritis Cartilage 22: 407-414, 2014.

4. Vaz MA, Baroni BM, Geremia JM, Lanferdini FJ, Mayer A, Arampatzis A and Herzog W: Neuromuscular electrical stimulation (NMES) reduces structural and functional losses of quadriceps muscle and improves health status in patients with knee osteoarthritis. J Orthop Res 31: 511-516, 2013.

5. Brouwers H, von Hegedus J, Toes R, Kloppenburg M and Ioan-Facsinay A: Lipid mediators of inflammation in rheumatoid arthritis and osteoarthritis. Best Pract Res Clin Rheumatol 29: 741-755, 2015. 
6. Yu H, Ye WB,Zhong ZM, Ding RT and Chen JT: Effect of advanced oxidation protein products on articular cartilage and synovium in a rabbit osteoarthritis model. Orthop Surg 7: 161-167, 2015.

7. Qin J, Shang L, Ping AS, Li J, Li XJ, Yu H, Magdalou J, Chen LB and Wang H: TNF/TNFR signal transduction pathway-mediated anti-apoptosis and anti-inflammatory effects of sodium ferulate on IL-1 $\beta$-induced rat osteoarthritis chondrocytes in vitro. Arthritis Res Ther 14: R242, 2012.

8. Benedetti S, Canino C, Tonti G, Medda V, Calcaterra P, Nappi G, Salaffi F and Canestrari F: Biomarkers of oxidation, inflammation and cartilage degradation in osteoarthritis patients undergoing sulfur-based spa therapies. Clin Biochem 43: 973-978, 2010.

9. Wang Q, Wu T, Chen X, Ni J, Duan X, Zheng J, Qiao J, Zhou L and Wei J: Puerarin injection for unstable angina pectoris. Cochrane Database Syst Rev: CD004196, 2006.

10. Zhou YX, Zhang H and Peng C: Puerarin: A review of pharmacological effects. Phytother Res 28: 961-975, 2014.

11. Wu J, Zhang X and Zhang B: Efficacy and safety of puerarin injection in treatment of diabetic peripheral neuropathy: A systematic review and meta-analysis of randomized controlled trials. J Tradit Chin Med 34: 401-410, 2014.

12. Yang Y, Chin A, Zhang L, Lu J and Wong RW: The role of traditional Chinese medicines in osteogenesis and angiogenesis. Phytother Res 28: 1-8, 2014.

13. Livak KJ and Schmittgen TD: Analysis of relative gene expression data using real-time quantitative PCR and the 2(-Delta Delta C(T)) Method. Methods 25: 402-408, 2001

14. Choa RM and Giele HP: Inter- and intrarater reliability of osteoarthritis classification at the trapeziometacarpal joint. J Hand Surg Am 40: 23-26, 2015.

15. Figueroa D, Calvo R, Villalón IE, Meleán P, Novoa F and Vaisman A: Clinical outcomes after arthroscopic treatment of knee osteoarthritis. Knee 20: 591-594, 2013.

16. Firuzi O, Spadaro A, Spadaro C, Riccieri V, Petrucci R, Marrosu G and Saso L: Protein oxidation markers in the serum and synovial fluid of psoriatic arthritis patients. J Clin Lab Anal 22: 210-215, 2008.

17. Nishimura S, Akagi M, Yoshida K, Hayakawa S, Sawamura T, Munakata $\mathrm{H}$ and Hamanishi C: Oxidized low-density lipoprotein (ox-LDL) binding to lectin-like ox-LDL receptor-1 (LOX-1) in cultured bovine articular chondrocytes increases production of intracellular reactive oxygen species (ROS) resulting in the activation of NF-kappaB. Osteoarthritis Cartilage 12: 568-576, 2004.
18. Zhang F, Guo X, Duan C, Wu S, Yu H and Lammi M: Identification of differentially expressed genes and pathways between primary osteoarthritis and endemic osteoarthritis (Kashin-Beck disease). Scand J Rheumatol 42: 71-79, 2013.

19. Kaufman GN, Zaouter C, Valteau B, Sirois P and Moldovan F: Nociceptive tolerance is improved by bradykinin receptor B1 antagonism and joint morphology is protected by both endothelin type A and bradykinin receptor B1 antagonism in a surgical model of osteoarthritis. Arthritis Res Ther 13: R76, 2011.

20. Levinger I, Levinger P, Trenerry MK, Feller JA, Bartlett JR, Bergman N, McKenna MJ and Cameron-Smith D: Increased inflammatory cytokine expression in the vastus lateralis of patients with knee osteoarthritis. Arthritis Rheum 63: 1343-1348, 2011

21. Arranz A, Gutiérrez-Cañas I, Carrión M, Juarranz Y, Pablos JL, Martínez C and Gomariz RP: VIP reverses the expression profiling of TLR4-stimulated signaling pathway in rheumatoid arthritis synovial fibroblasts. Mol Immunol 45: 3065-3073, 2008.

22. Klawitter M, Hakozaki M, Kobayashi H, Krupkova O, Quero L, Ospelt C, Gay S, Hausmann O, Liebscher T, Meier U, et al: Expression and regulation of toll-like receptors (TLRs) in human intervertebral disc cells. Eur Spine J 23: 1878-1891, 2014.

23. Takakubo Y, Barreto G, Konttinen YT, Oki H and Takagi M: Role of innate immune sensors, TLRs, and NALP3 in rheumatoid arthritis and osteoarthritis. J Long Term Eff Med Implants 24: 243-251, 2014

24. Kim BH,Lee JM,Jung YG, Kim S and Kim TY: Phytosphingosine derivatives ameliorate skin inflammation by inhibiting NF-kB and JAK/STAT signaling in keratinocytes and mice. J Invest Dermatol 134: 1023-1032, 2014.

25. Wang X, Liu Q, Ihsan A, Huang L, Dai M, Hao H, Cheng G, Liu Z, Wang Y and Yuan Z: JAK/STAT pathway plays a critical role in the proinflammatory gene expression and apoptosis of RAW264.7 cells induced by trichothecenes as DON and T-2 toxin. Toxicol Sci 127: 412-424, 2012.

26. Li R, Liang T, He Q, Guo C, Xu L, Zhang K and Duan X: Puerarin, isolated from Kudzu root (Willd.), attenuates hepatocellular cytotoxicity and regulates the GSK-3 $\beta /$ NF-kB pathway for exerting the hepatoprotection against chronic alcohol-induced liver injury in rats. Int Immunopharmacol 17: 71-78, 2013.

27. Zheng P, Ji G, Ma Z, Liu T, Xin L, Wu H, Liang X and Liu J: Therapeutic effect of puerarin on non-alcoholic rat fatty liver by improving leptin signal transduction through JAK2/STAT3 pathways. Am J Chin Med 37: 69-83, 2009. 